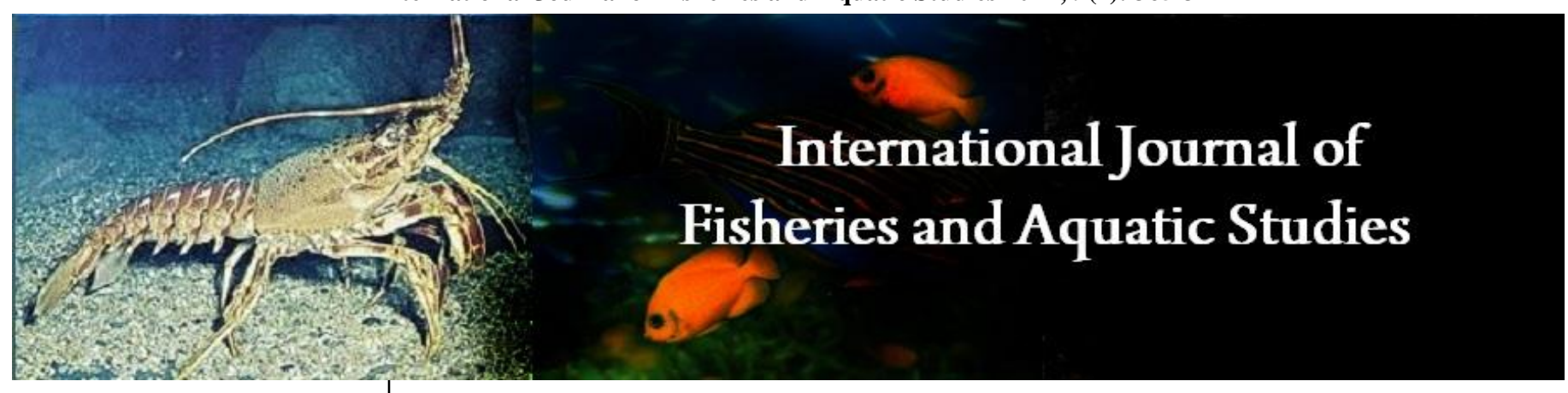

E-ISSN: 2347-5129

P-ISSN: 2394-0506

(ICV-Poland) Impact Value: 5.62

(GIF) Impact Factor: 0.549

IJFAS 2021; 9(1): 365-374

(C) 2021 IJFAS

www.fisheriesjournal.com

Received: 04-11-2020

Accepted: 06-12-2020

Pritiranjan Maiti

(1) Department of Chemistry,

Vidyasagar University,

Midnapore, West Bengal, India

(2) Coastal Ecology Research

Laboratory, Egra SSB College,

Purba Midnapore, West Bengal,

India

Amiya Kumar Panda

Department of Chemistry,

Vidyasagar University,

Midnapore, West Bengal, India

Sudipta Kumar Ghorai

Coastal Ecology Research

Laboratory, Egra SSB College,

Purba Midnapore, West Bengal,

India

Corresponding Author:

Sudipta Kumar Ghorai

Coastal Ecology Research

Laboratory, Egra SSB College,

Purba Midnapore, West Bengal,

India

\section{Study of salinity infiltration in soil due to vannamei shrimp farming in the adjoining area of Contai, Purba Medinipur, West Bengal, India and its immediate economic effect}

\author{
Pritiranjan Maiti, Amiya Kumar Panda and Sudipta Kumar Ghorai
}

DOI: https://doi.org/10.22271/fish.2021.v9.i1e.2422

\begin{abstract}
Brackish water aquaculture (presently vannamei shrimp farming) has been increasing rapidly due to gain of higher profits than traditional agriculture or fishery in the coastal areas and it has been playing important roles on the socio-economic development of Contai under Purba Medinipur district of West Bengal, India. It provides quick economic benefits with earning of foreign currency and simultaneously alleviates poverty through employment-generation, creates scope of engagement for the rural and marginal villagers. Although vannamei shrimp farming has contributed a positive impact on the socioeconomic scenario of the area, nevertheless has always been subjected to lots of negative environmental consequences as well as thousands of questions regarding crop-productivity, future food-security and challenges towards sustainable development. Substantial leakage, seepage, and overflow of saline water into the nearest agricultural lands has been diminishing the fertility and crop-productivity. As a result, areas of agricultural land are being reduced and land-conversion to shrimp farms is increasing the rise. The rapid increase of farming area has direct and indirect effect especially on agriculture. Moreover, due to continued shrimp farming in the same plots the soil properties of those ponds along with species composition have been changing and those lands are badly becoming barren. As an immediate effect, yield of shrimp as well as income from this sector is reducing with each year.
\end{abstract}

Keywords: employment-generation, salinity infiltration, shrimp farming, socio-economic development, sustainable development

\section{Introduction}

The coastal belt of the Bay of Bengal of Contai, West Bengal, India was once enriched with a rich variety of ecologically important crops and fishes. But to achieve quick economic benefit present trend is to convert cultivable agricultural lands and marshes into shrimp farms since almost three decades. Brackish water farming was started in this area since 2012 [1]. Unfortunately, due to the lack of scientific methods and policies for proper ways of conversion of lands and pisciculture techniques, many adverse effects have emerged in recent years. The consequences include misuse and inundation of saline water carried into the canals and their drains from the Bay of Bengal or its creeks. Leakage, seepage and overflow of saline water to the nearby agricultural lands have lasting effects, changing the hydrology that provides the foundation of wetland ecosystems ${ }^{[2,3]}$. Seepage and discharge of saline water into the ponds result in the salinity changes in ground water also ${ }^{[4]}$. Quality of soil depends on the soil nutrients like organic $\mathrm{C}, \mathrm{N}, \mathrm{K}$, and $\mathrm{P}$, because all physical, chemical and biological properties significantly depend on these parameters ${ }^{[5-7]}$. Physico-chemical properties of soil are mainly governed by soil salinity ${ }^{[8]}$. Crop production get severely hampered due to increased soil salinity ${ }^{[9]}$, hence the regular and poor farmers become reluctant to cultivate their lands. Soil degradation due to saline infiltration has forced the poor farmers to sell their lands to the rich farmers or large shrimp companies. Due to social-insecurity land owners are compelled to lease their lands also. On the other hand, indiscriminate uses of chemicals for farming are likely to be very sensitive to the overall environment ${ }^{[10]}$. As the commercial shrimp farming has been associated with a lot of negative environmental and social impacts it hinders the 
sustainable development of the area. So, there is a great threat towards long term sustainability of the shrimp culture [11]. Ecological impacts include some deterioration of soil and water quality, depletion of mangrove forest ${ }^{[12-16]}$, degradation of other important wetland habitats, such as salt marshes, and even freshwater wetlands ${ }^{[17-18]}$, decrease in population of native fish and shellfish species etc. There have also been some socioeconomic consequences, most acutely on the livelihood patterns of people particularly among the poor and unskilled living in coastal areas and on rural to urban migration ${ }^{[19]}$. The entire process affected badly the soil and agriculture yields, ecology, biodiversity and sustainability in the coastal regions of our country. Due to lack of scientific and proper management system shrimps are being attacked by different type of diseases ${ }^{[20]}$ - which spread easily. So, yields in shrimp and expected incomes from this sector have been decreasing. Also, the excess use of medicines and chemicals in the shrimp farm bears a long-term ecological threat to the larger portion of the costal population in near future.

At this stage, we believe, the different policy making bodies/agencies have important role in formulating policy, monitoring or stimulating for sustainable development.

\section{Materials and Methods}

This study is being performed on the basis of extensive survey of study area, related literature review, experimental documentary analysis and field observation to know the land scape, socio-economic and socio-cultural scenario of this study area. Relevant data and information is being collected from both the primary and secondary sources.

Readings of salinity (by following the standard Strickland and
Parsons method), dissolved ammonia (by Liddicoat method), nitrite (by Shinn method), alkalinity (carbonate, bicarbonate) (by Anderson and Robinson method), total hardness (EDTA method), pH (using TOA, model number WQC22A, Japan), growth of prawn, etc., have been recorded time to time following the standard protocol in the selected ponds of the study area. Various chemical analysis test-kits especially of HiMedia Lab. Pvt. Ltd. have been used. Scientific facilities of the Coastal Ecology Research Laboratory, Egra SSB College, Purba Medinipur is also being utilized extensively for various tests.

Secondary sources like reports of the Census of India [21], 2011 and other Survey Institutions and recent research papers, books, journals, records etc. have been used for collecting information. People's Biodiversity Register [22], 2015 of Nayaput Gram Panchayet under Contai-I Block, Purba Medinipur, West Bengal, India, prepared by Contai - I Biodiversity Management Committee, West Bengal Biodiversity Board (where the author is the Secretary) is also very helpful. Some data and information have been collected by local interview, i.e., through community based data collection administering a number of structured charts followed by questionnaires. Respondents have been selected on random sampling.

\section{Results}

As listed below, eighteen (18) revenue villages out of thirty nine revenue villages of Nayaput Gram Panchayet under Contai-I Block is selected for this field study and data collection. Data for the shrimp farming area from 2000 to 2020 have been obtained by local survey (Figure 1).

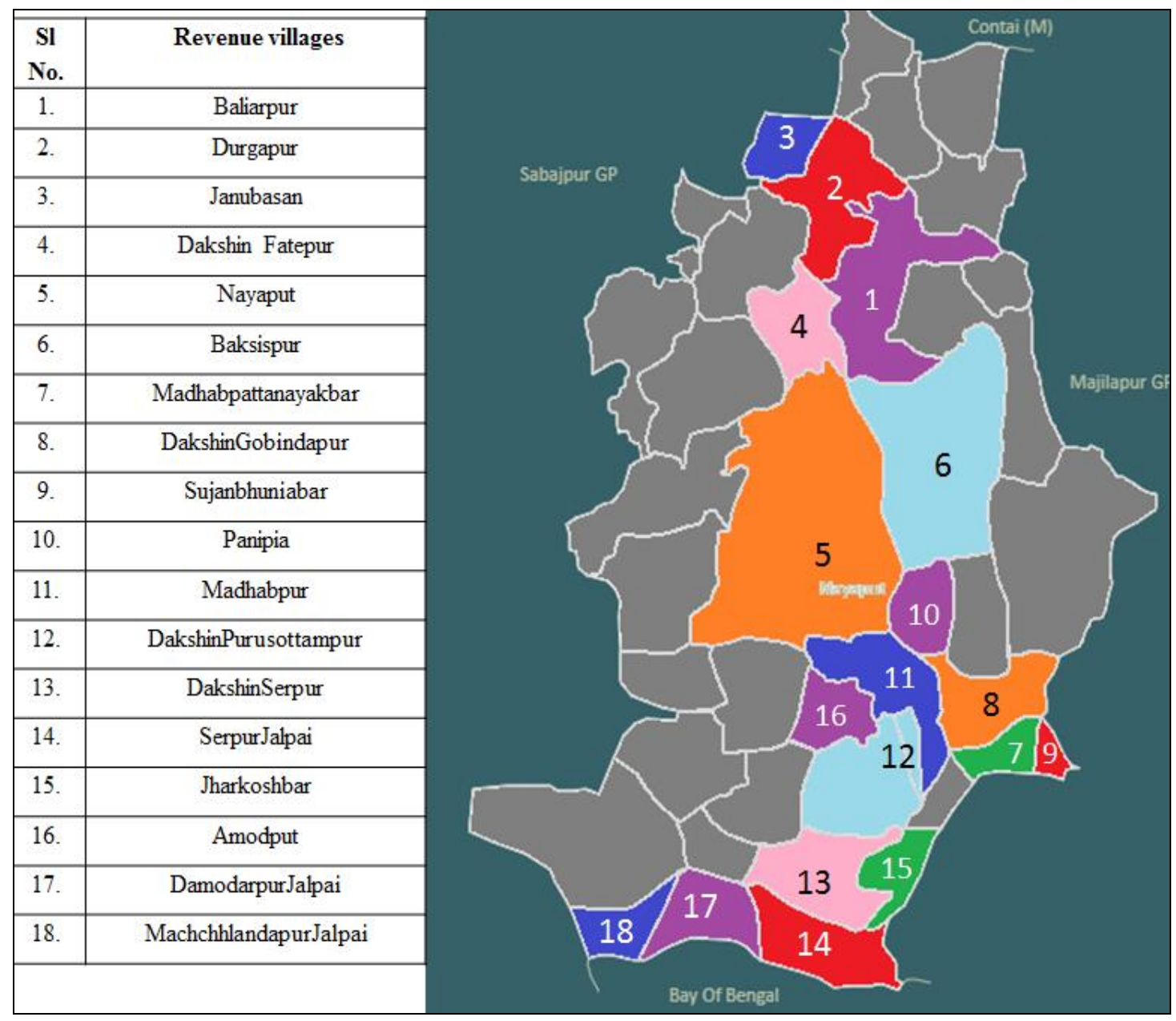

Fig 1: Map of Nayaput Gram Panchayet and the selected eighteen (18) revenue villages. 
A closure look into the land use data revealed the distribution pattern of the shrimp farming areas (Table 1). Initially, the marshes areas, the coastal revenue villages, were mostly used for shrimp farming in Damodarpur Jalpai, Machchhlandapur Jalpai and Serpur Jalpai revenue villages (Figure 1, S1. No. $14,17,18)$. The heat-map comparison of the study areas from Table 1 in 2000and 2020 (Figure 2) clearly indicates that, over the decade, the shrimp pond area has extended inwards from the coastal areas and to fertile agriculture lands, as well as even to some domestic ponds. Again, an insightful search into the area survey data revealed that within the marshes areas, more and more shrimp culture areas have become waste lands and not useable for further aquaculture. As a result, the total areas for shrimp culture have been reduced sufficiently in 2020 (Figure 2).

Table 1: Year-wise data of shrimp farming areas of the selected revenue villages ${ }^{\mp}$.

\begin{tabular}{|c|c|c|c|c|c|c|c|c|c|}
\hline \multicolumn{19}{|c|}{ Study Area } \\
\hline \multirow{2}{*}{ SI No. } & \multirow{2}{*}{ Revenue village } & \multirow{2}{*}{ Total Area } & \multicolumn{4}{c|}{ Shrimp farming Area (Nearly) in Acre } \\
\cline { 5 - 10 } & & & $\mathbf{2 0 0 0}$ & $\mathbf{2 0 0 7}$ & $\mathbf{2 0 1 2}$ & $\mathbf{2 0 1 6}$ & $\mathbf{2 0 1 8}$ & $\mathbf{2 0 1 9}$ & $\mathbf{2 0 2 0}$ \\
\hline 1 & Baliarpur & 216.45 & 0 & 0 & 0 & 1 & 2 & 4 & 5 \\
\hline 2 & Durgapur & 174.27 & 0 & 2 & 3 & 5 & 6 & 6 & 8 \\
\hline 3 & Janubasan & 64.94 & 0 & 1 & 2 & 4 & 8 & 8 & 9 \\
\hline 4 & DakshinFatepur & 108.57 & 0 & 2 & 6 & 8 & 10 & 10 & 14 \\
\hline 5 & Nayaput & 664.61 & 6 & 8 & 12 & 15 & 20 & 24 & 23 \\
\hline 6 & Baksispur & 405.56 & 2 & 10 & 16 & 25 & 30 & 30 & 31 \\
\hline 7 & Madhabpattanayakbar & 81.96 & 12 & 16 & 17 & 18 & 20 & 21 & 21 \\
\hline 8 & DakshinGobinda-pur & 42.13 & 15 & 15 & 18 & 18 & 20 & 20 & 19 \\
\hline 9 & Sujanbhuniabar & 24.19 & 6 & 8 & 10 & 12 & 15 & 15 & 15 \\
\hline 10 & Panipia & 99.78 & 14 & 20 & 22 & 24 & 25 & 25 & 25 \\
\hline 11 & Madhabpur & 165.91 & 25 & 28 & 30 & 32 & 35 & 35 & 34 \\
\hline 12 & DakshinPurusottampur & 48.11 & 25 & 26 & 28 & 30 & 30 & 30 & 29 \\
\hline 13 & DakshinSerpur & 164.73 & 30 & 35 & 42 & 46 & 50 & 53 & 50 \\
\hline 14 & SerpurJalpai & 149.29 & 140 & 140 & 140 & 140 & 140 & 140 & 130 \\
\hline 15 & Jharkoshbar & 58.41 & 5 & 6 & 7 & 8 & 10 & 10 & 10 \\
\hline 16 & Amodput & 70.58 & 10 & 12 & 15 & 22 & 25 & 25 & 26 \\
\hline 17 & DamodarpurJalpai & 105.68 & 105 & 105 & 105 & 105 & 105 & 105 & 100 \\
\hline 18. & Machchhlandapur Jalpai & 79.33 & 79 & 79 & 79 & 79 & 79 & 79 & 70 \\
\hline & Total & $2,724.5$ & 474 & 513 & 552 & 592 & 630 & 640 & 619 \\
\hline
\end{tabular}

${ }^{\mathrm{T}}$ Total geographical area data was collected from Census of India, 2011 and data for shrimp farming area was collected by local survey

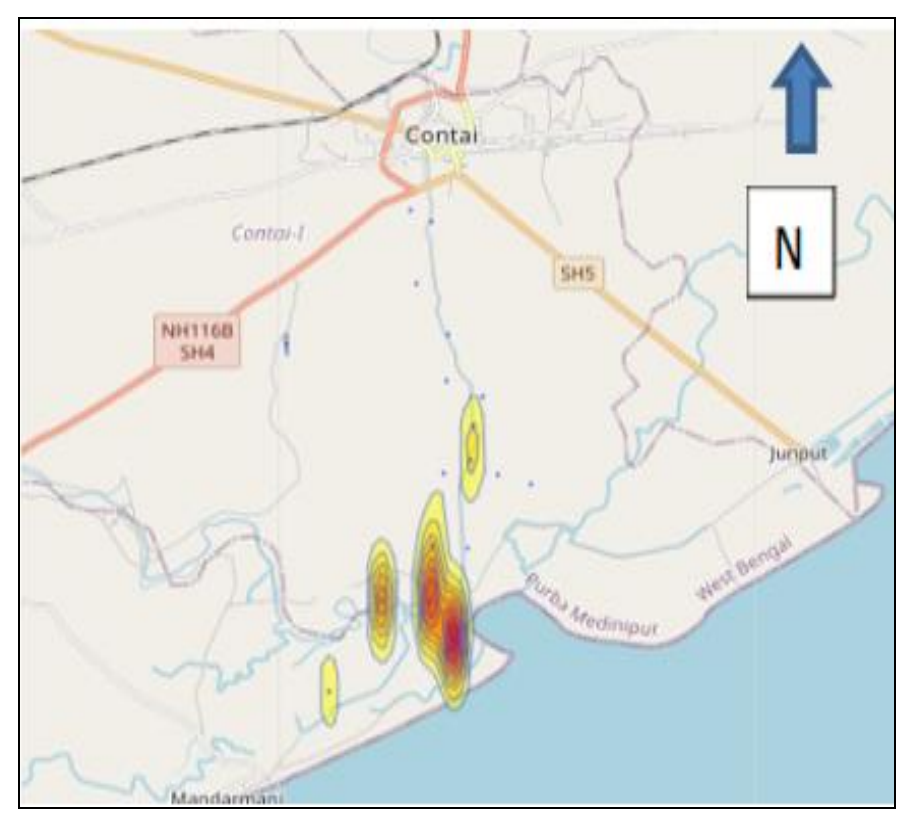

2000



2020

Fig 2: Comparison between heat-maps of Shrimp farming areas of $2000 \& 2020$.

Moreover, when the land use pattern in 2003 is compared to that of 2020, this abrupt change is more visible (Figure 3, 4). The coastal revenue village of DamodarpurJalpai (Sl. No. 17, Table 1) showed the occurrence of a huge number of ponds from bigger natural marshes and ponds (Figure 3). In the interior revenue village of Nayaput (Table 1), a large part of agricultural land has been converted to brackish water shrimp culture ponds (Figure 4). It is important to state that, in the interior revenue villages, the surrounding areas of shrimp ponds are traditionally used for agriculture purpose and therefore, are most vulnerable due to salinity infiltration from the nearby brackish water shrimp farms. 


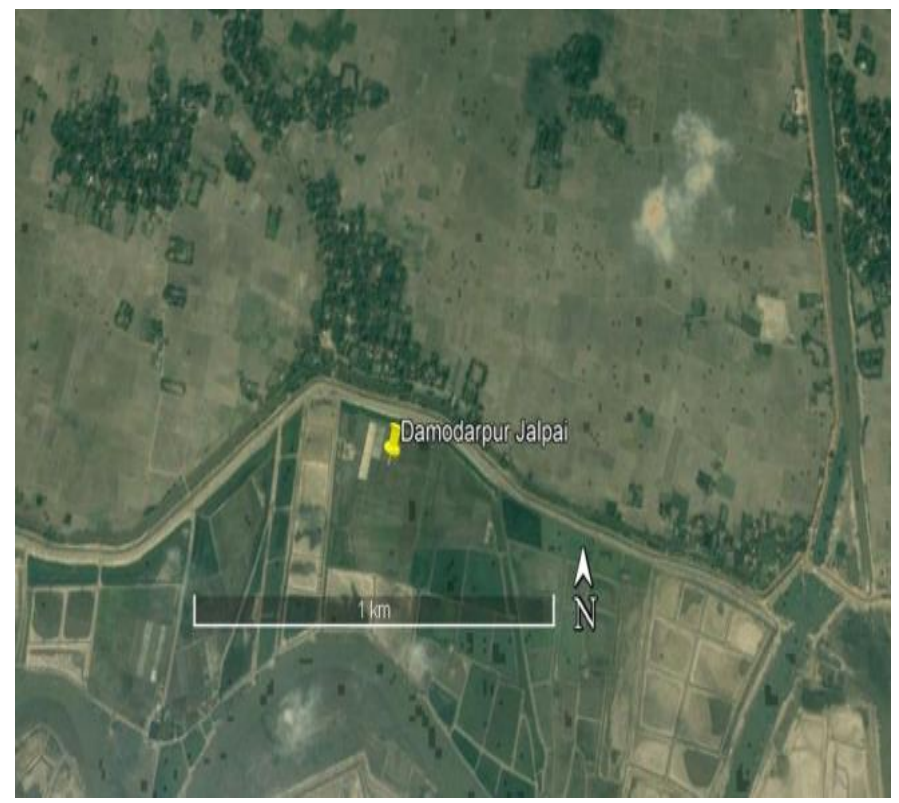

2003

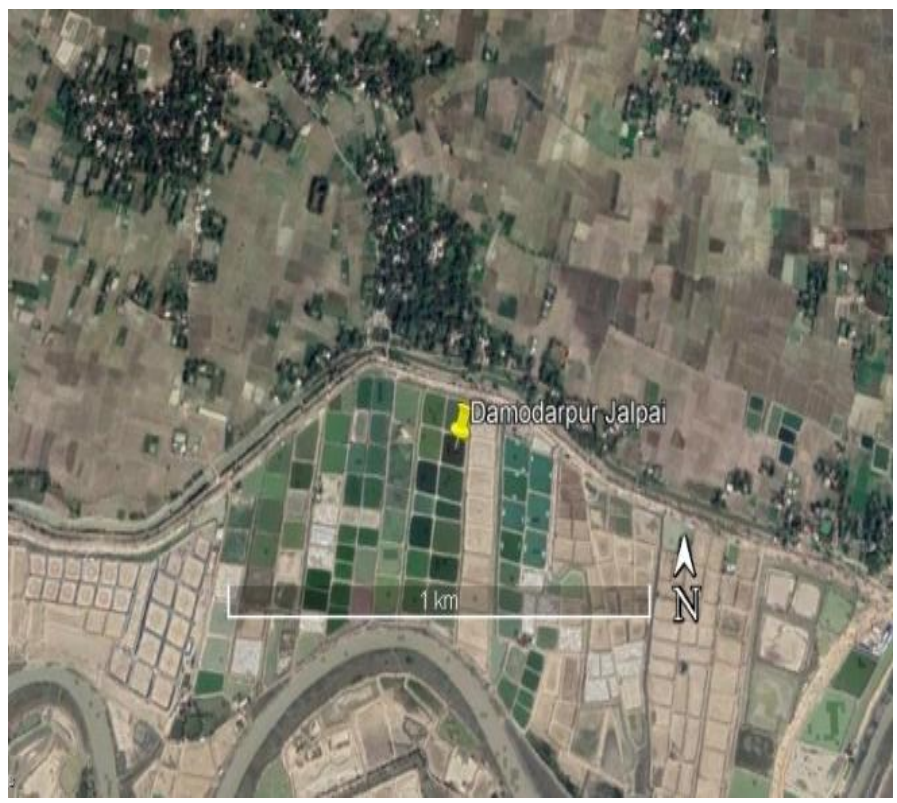

2020

Fig 3: Comparison of land use pattern of Revenue village DamodarpurJalpai(Source: Google Earth)

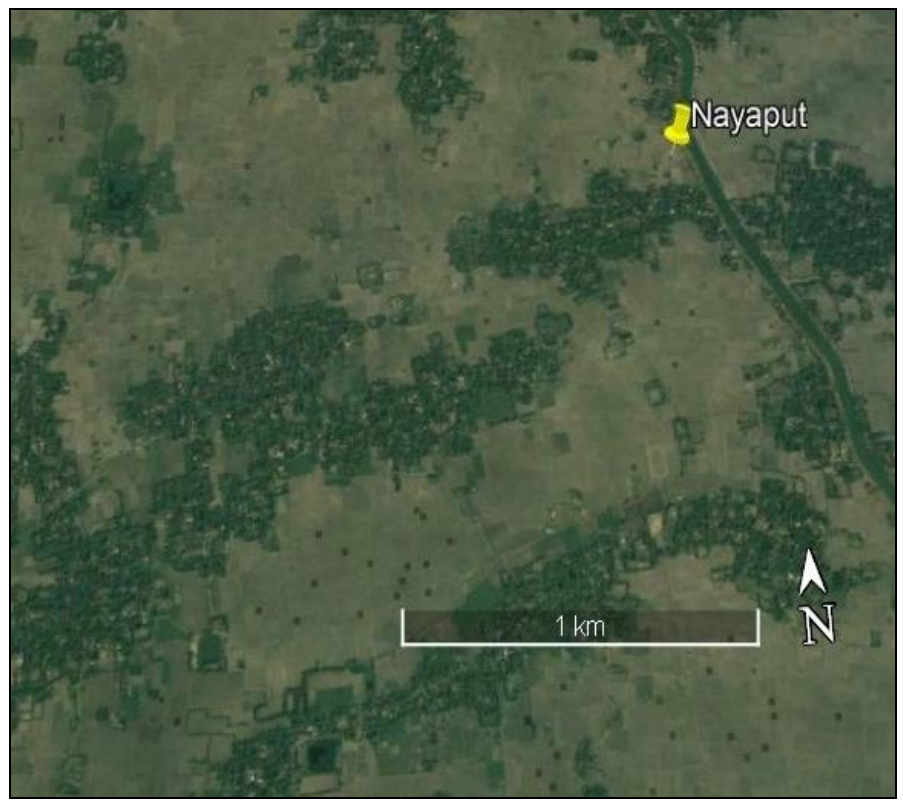

2003

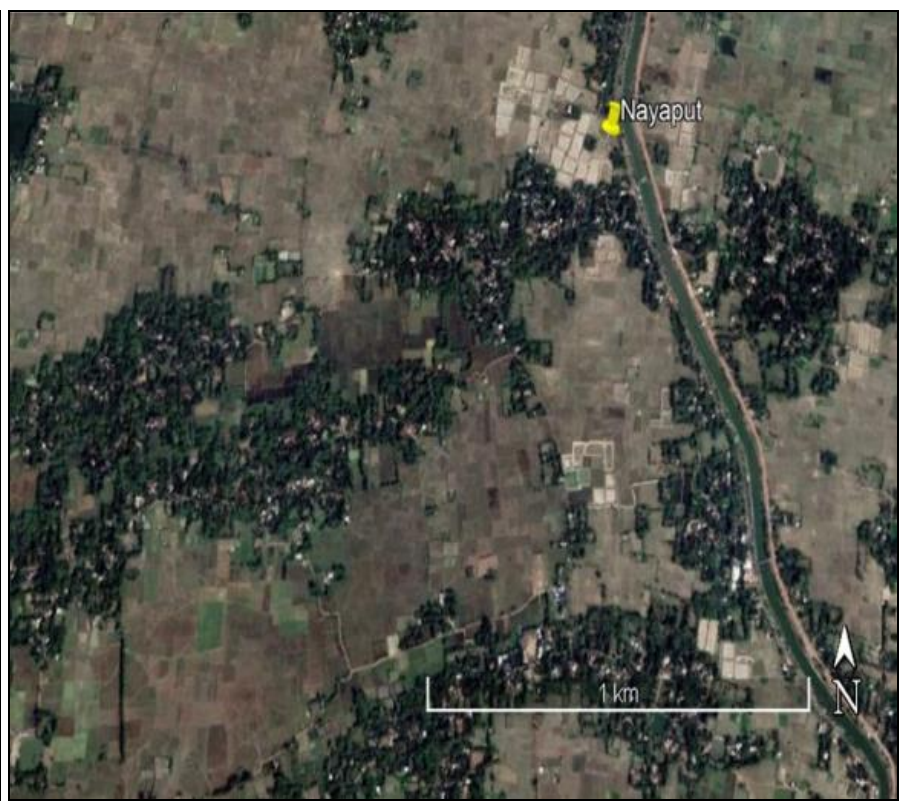

2020

Fig 4: Comparison of land use pattern of Revenue village Nayaput (Source: Google Earth)

A comparison and co-relation can be drawn between the agriculture land and shrimp farming areas (Figure 5). Data for the land use pattern were collected in all of the study areas from 2000 to 2020. The graphical comparison of agriculture land and shrimp farming area shows that new shrimp farms have been created in expense of fertile agriculture lands up to the year 2019 in average. Interestingly, from 2018 to 2019 , there is an exponential decrease in agriculture land; however, the growth of total shrimp farm remained low. This is due to the fact that, a large number of previously operating farms have been discarded due to low productivity and newer farms have been created using agriculture lands. This leads to a low net increase in total shrimp farming area and also an increase in barren lands and unused ponds. This effect is more prominent in 2020, where an even larger number of unproductive shrimp farms have become wasteland leading to sharp decrease in total shrimp farming areas. 


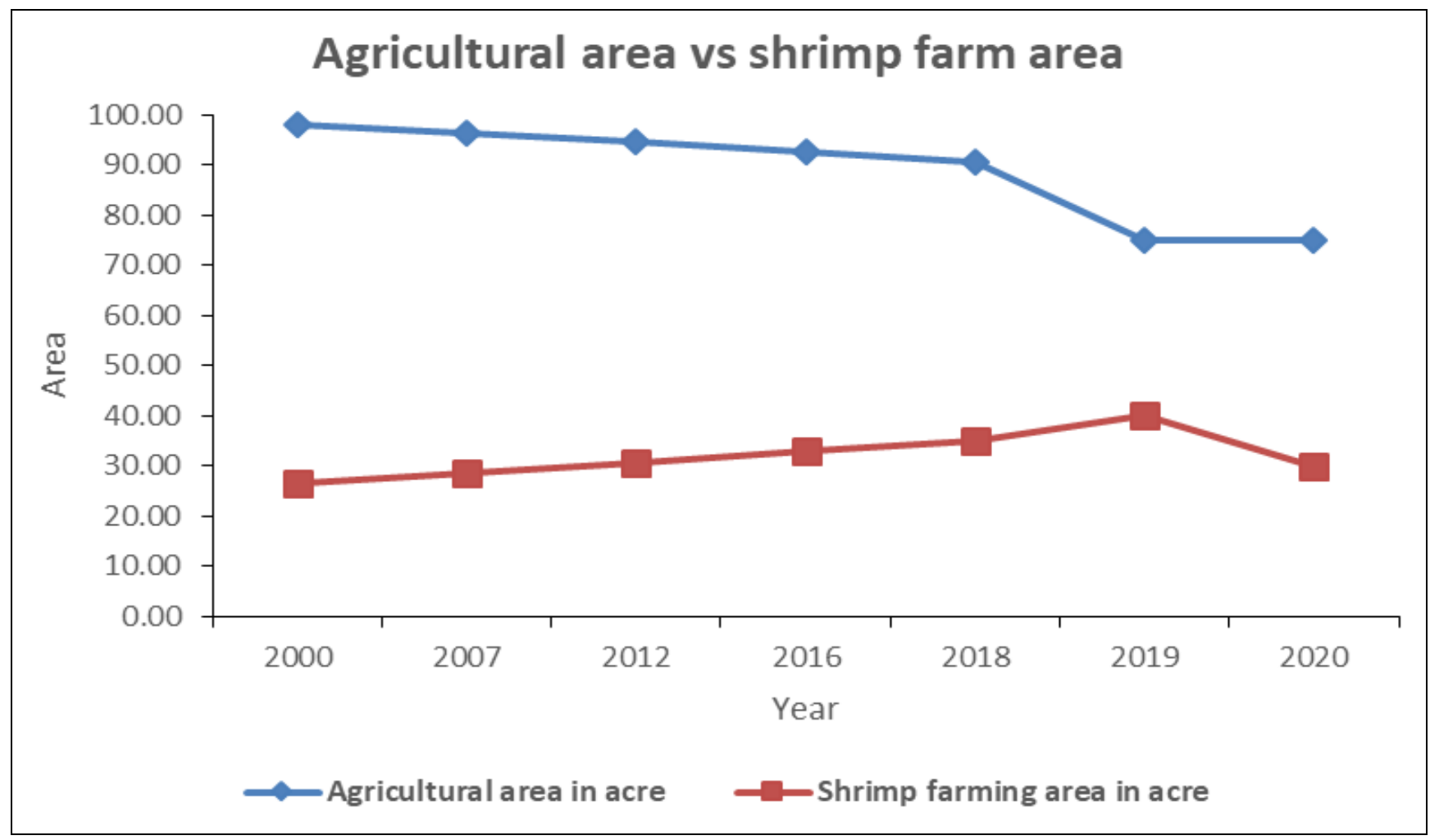

Fig 5: Comparison and co-relation between the agriculture land and shrimp farming areas

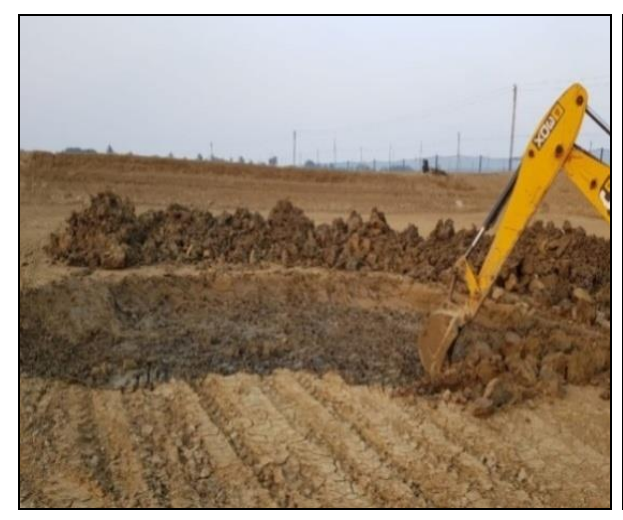

A.



D.

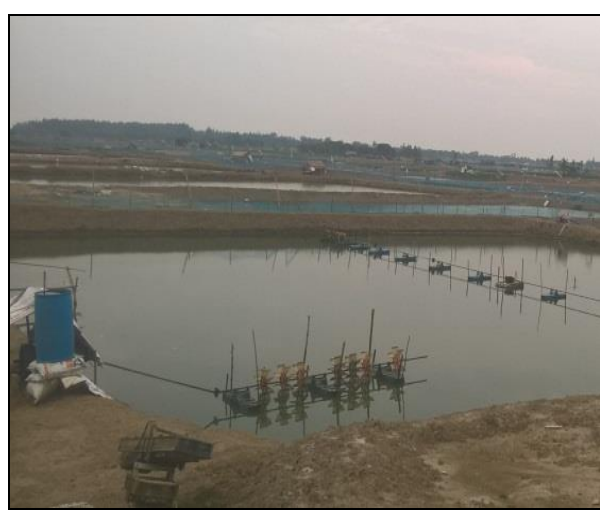

B.

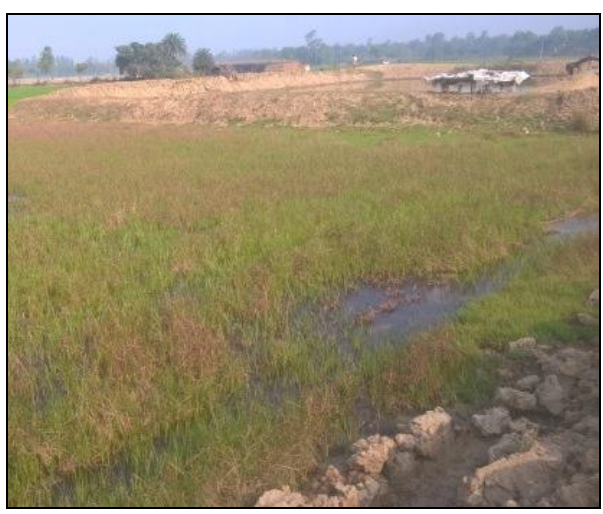

E.

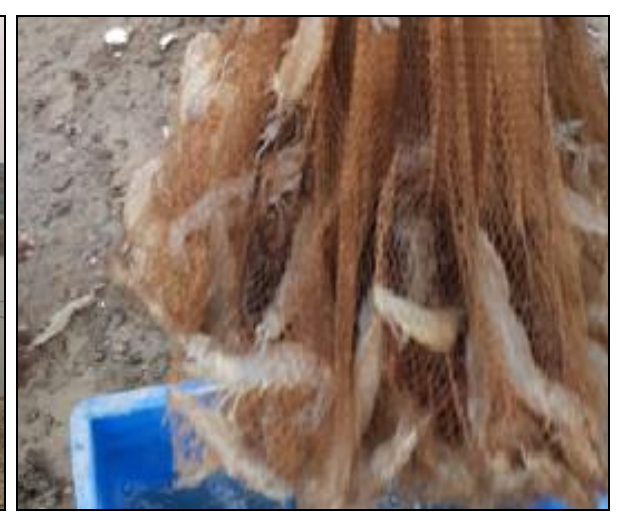

C.

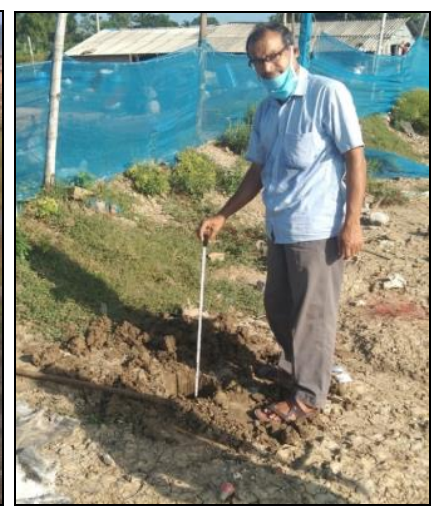

F.

Fig 6:a) Digging of the pond; b) Vannamei pond during culture; c) Vannamei caught in the net; d) Rice seedlings dying due to salinity infiltration; e) Agriculture land permanently became wasteland due to salinity infiltration; f) Picture of author collecting the soil samples.

\subsection{Salinity infiltration}

Salinity infiltration effect in the vicinity of treated brackish water shrimp farming ponds was initially studied. The results are summarized in Figure 7. Elevated salinity is found as far as up to $45 \mathrm{ft}$ from the edge of the culture ponds in average. In the immediate vicinity of the pond, in the first $15 \mathrm{ft}$, the salinity is extremely high; up to 12.7 parts per trillion (ppt) the next $15 \mathrm{ft}$ stretches has the salinity of $6.9 \mathrm{ppt}$ to $8.2 \mathrm{ppt}$. Next $15 \mathrm{ft}$ length has salinity value from $1.8 \mathrm{ppt}$ to $2.8 \mathrm{ppt}$. 


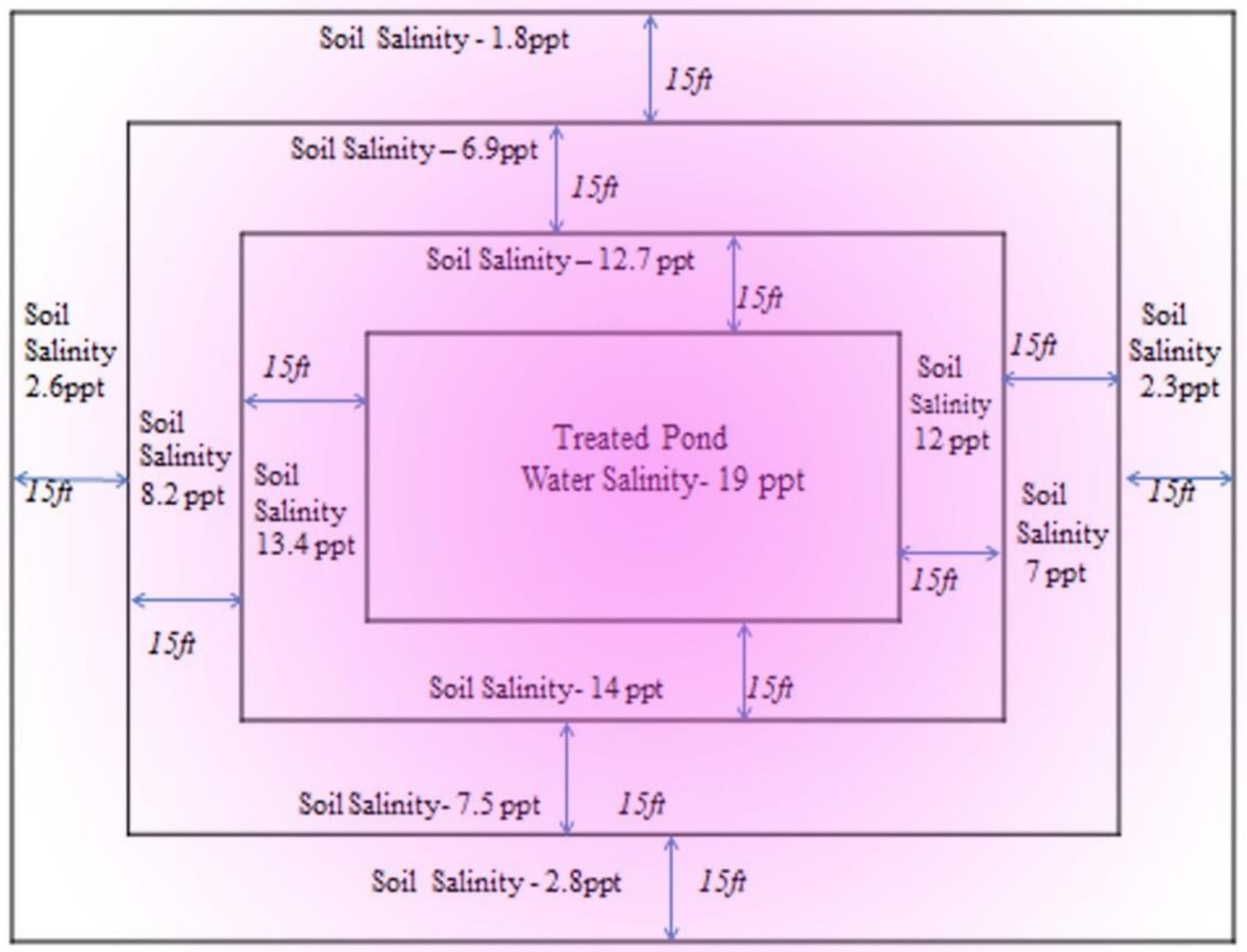

Fig 7: Salinity infiltration around the shrimp farming pond (on $2^{\text {nd }}$ year of farming, first culture).

This high salinity lead to the change in soil properties and as a direct consequence, the species composition is also changing rapidly. Due to infiltration of salinity the fertility of the cultivated lands of surrounding farm areas are largely aggrieved, paddy and crop cultivation is largely being hampered (Figure6d).

The first culture of shrimp almost coincides yearly with 'Boro paddy' (rice cultivated in pre-monsoon period)with high yielding rice species. During summer in the early stage of farming, the low rainfall along with external irrigation of sea water lead to high salinity infiltration to the nearest agriculture lands from the shrimp ponds leading to vast destruction in rice farming. This effect is less prominent in the second culture; where the high monsoon rainfall reduces the salinity of the shrimp pond, as well as washes way the excess salinity from farm land, leading to lower degree of salinity in rice fields of immediate vicinity.

\subsection{Shrimp Culture periods}

Generally in this study area shrimp cultures are being done twice a year in the same pond. First culture is in the period May-June to August-September and the second culture is during the period from September to December. Pond is prepared first for culture. Saline water of the ocean is poured into the ponds. Then the water is bleached and after that seeds of prawn are cultured in those ponds commercially.

\subsection{Physiochemical parameters}

Eight sample ponds in the study area were selected for data collection. Readings of salinity, dissolved ammonia, nitrite, alkalinity (carbonate, bicarbonate), total hardness, $\mathrm{pH}$, etc., have been recorded time to time in the same eight ponds of the study area. As the study area contains live ponds, we did not hamper the farming environment in any way. So, all the ponds are used for commercial culture and all the physicochemical parameters were maintained within permissible limit for optimum shrimp growth. Salinity is maintained between the ranges 14 to $19 \mathrm{ppt}$ in the treated pond. Below this salinity growth will not be proper. In general, salinity decreases with increase in culture period. Among all the parameters ammonia is the most important factor that increases with the growth of shrimps. In all the controlled and treated ponds, the level of ammonia has been maintained within $0.3 \mathrm{ppm}$ during 65 to 70 days of culture.

\subsection{Growth and surviving ability status of the shrimps}

The growth of shrimp is recorded in regular interval over the entire lifetime. Weight of the shrimp increases normally with increase in number of days (Figure 8). The growth for first culture has been compared with second culture. It has been found that, for all eight ponds, the growth decreases in second culture (Figure9). This effect can be attributed to the fact that, the water quality, salinity and the other physico-chemical parameters of ponds deteriorates after first culture during rainy season. 


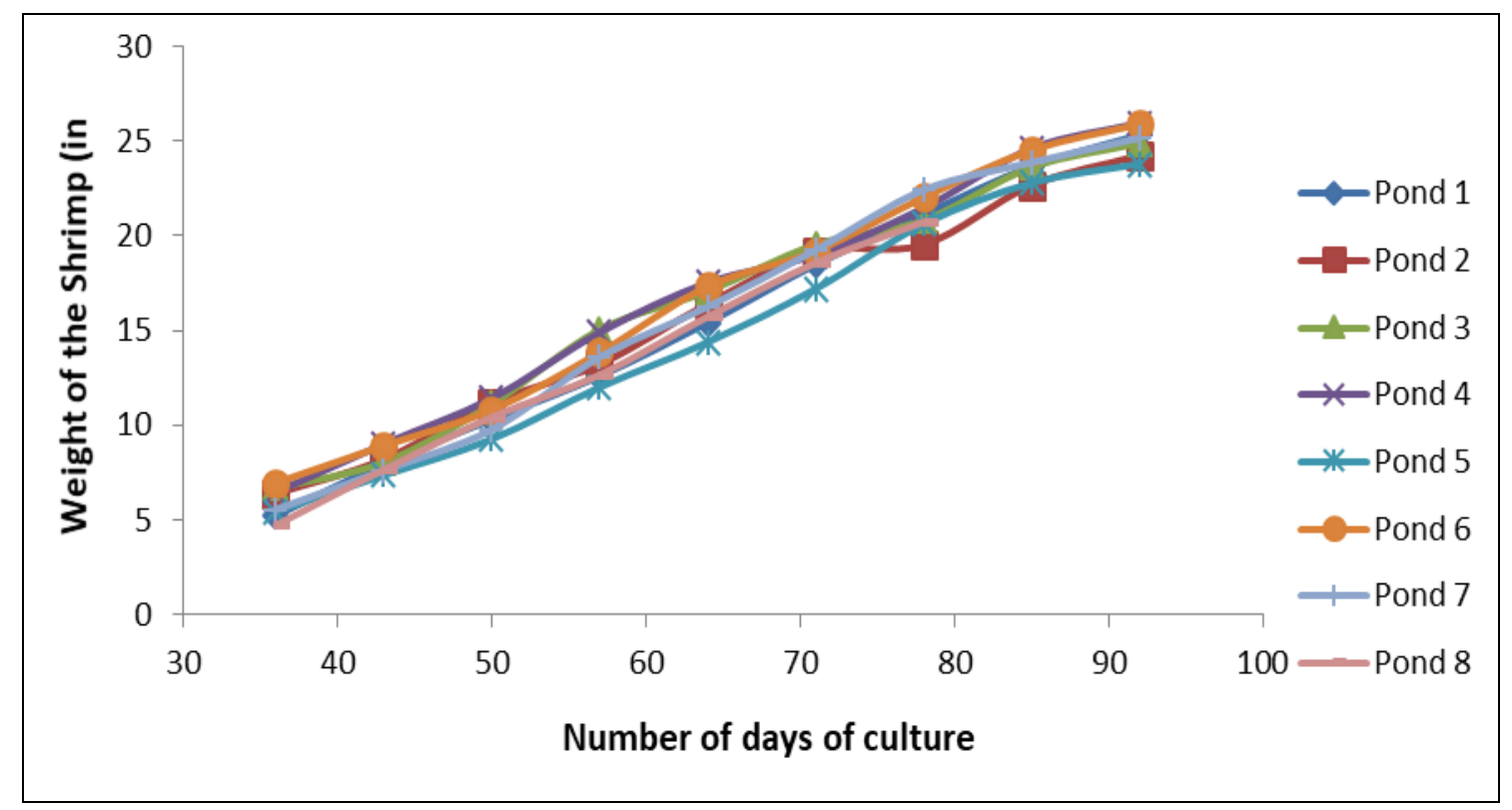

Fig 8: Day-wise data of growth of shrimps in the selected ponds

The surviving ability status of the shrimps has been measured year wise in two both first and second cultures. Over the years, the surviving ability of the shrimps decreased in any specific culture pond. This can also be rationalized by the same fact as before. Due to the reduction of physic-chemical parameters and soil quality, the fertility of the pond also decreases. The same falling trend is also prominent, when first and second culture is compared (Figure 9). On the other hand, year-wise comparison of average yield of shrimp vs shrimp farming area showed that, average yield of shrimp has decreased over the years despite an increase in the total shrimp farming area (Figure 10).

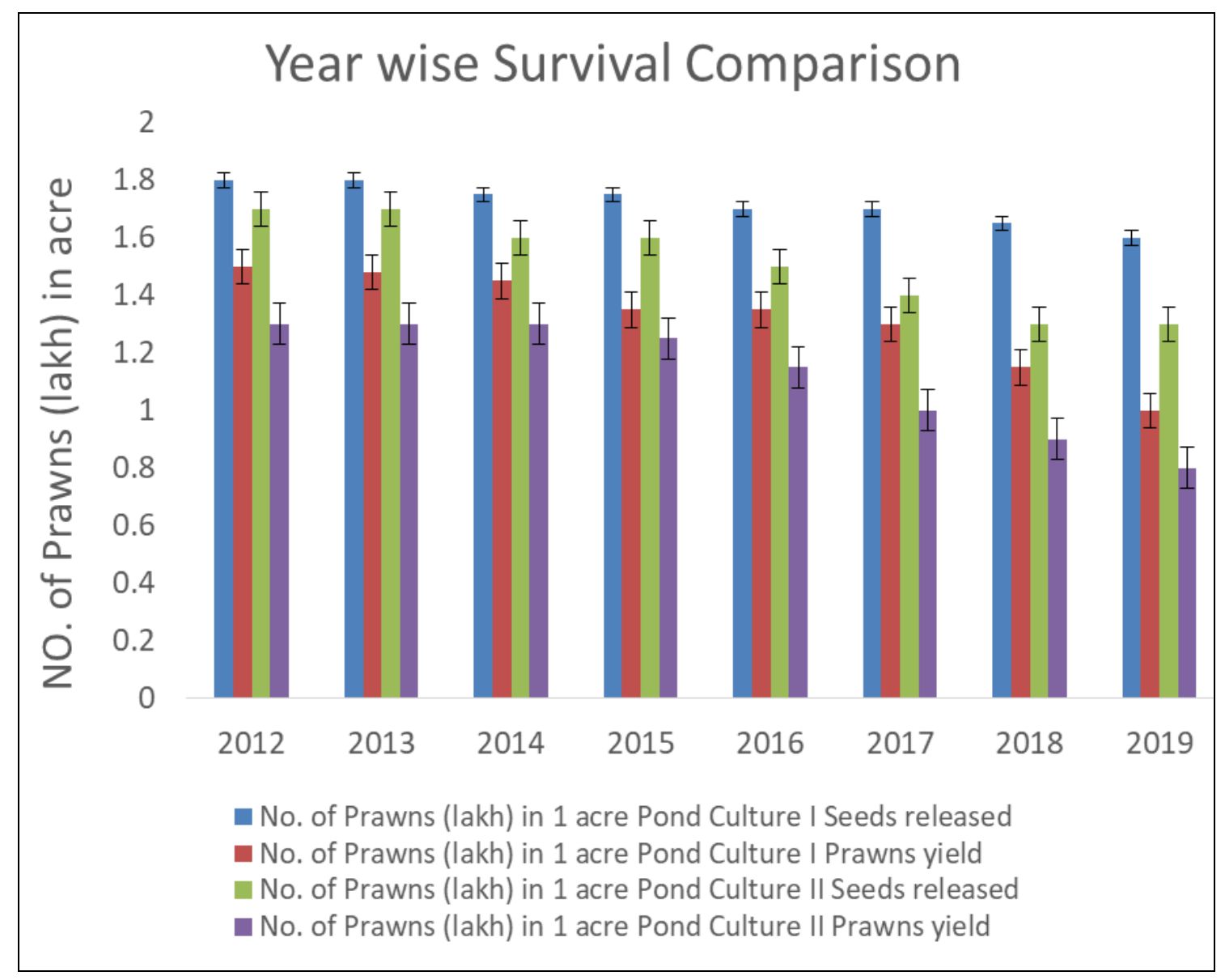

Fig 9: Year-wise data of surviving ability of shrimps in the selected ponds. 


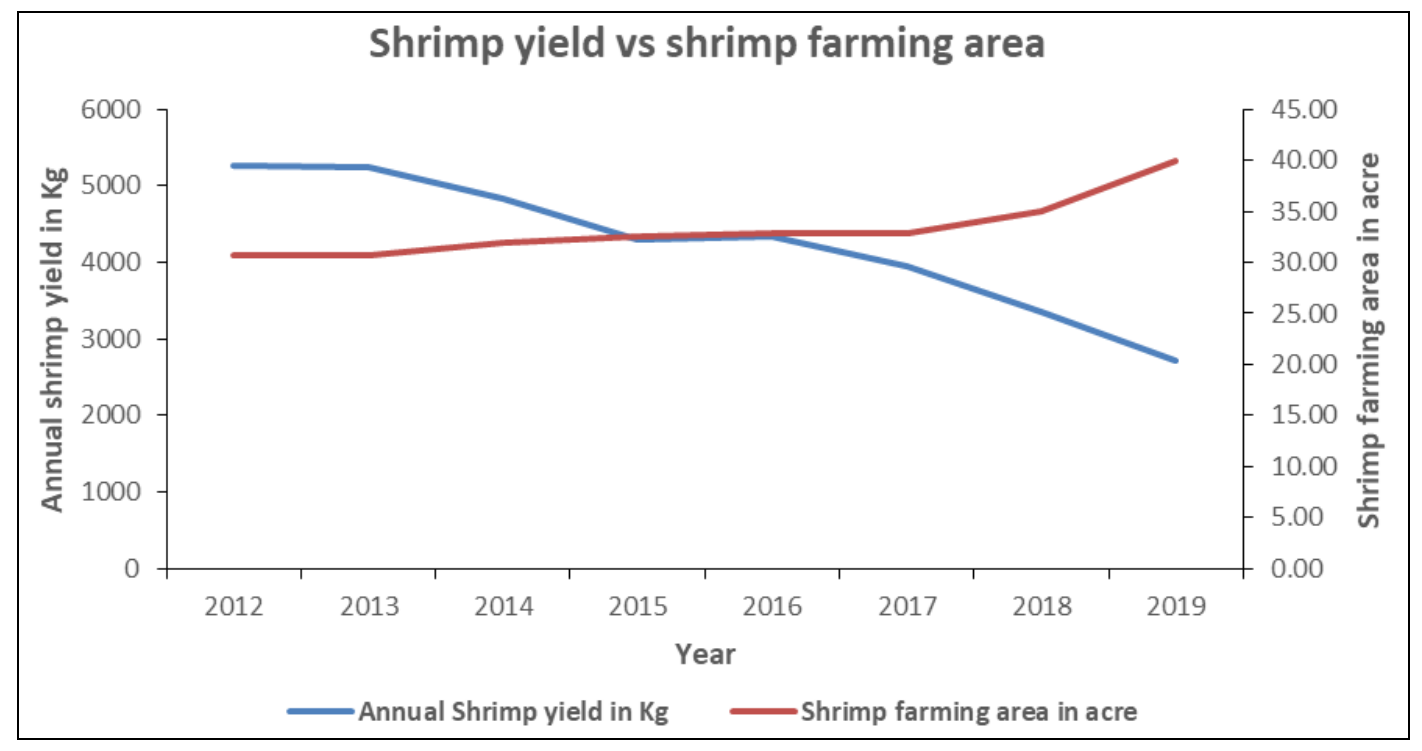

Fig 10:Year-wise comparison of average yield of shrimp $v s$. shrimp farming area

\section{Year-wise yield and income}

Year-wise yield and year-wise income have been analyzed.

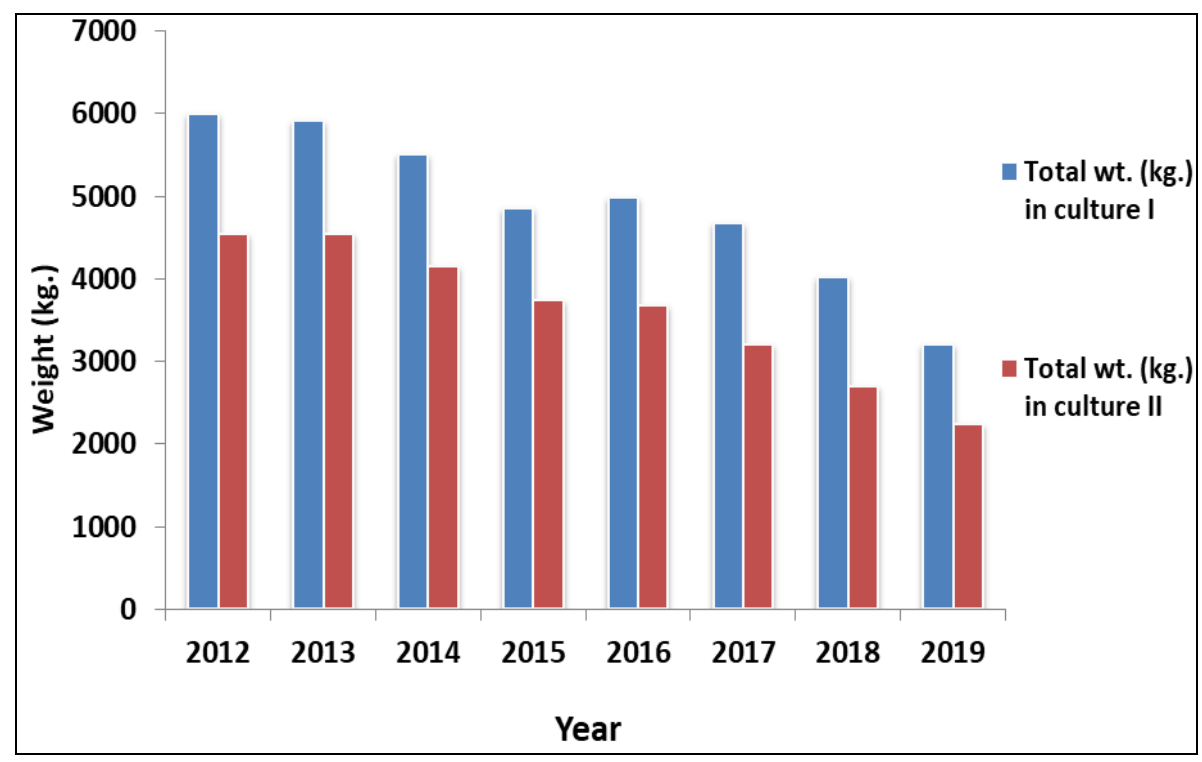

Fig 11: Year-wise data of yields of shrimps.

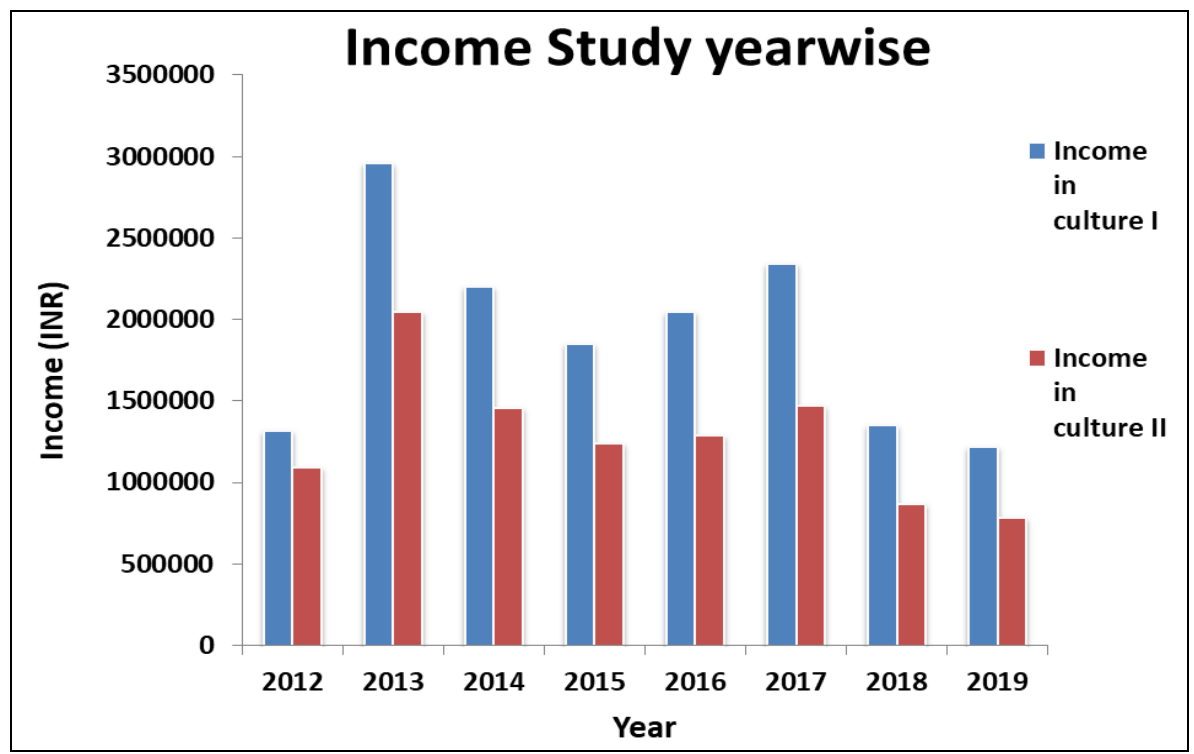

Fig 12: Year-wise data of income (in Indian Rupee, INR) from shrimp culture. 
The above data of year-wise yield and year-wise income trend points towards the imminent threat to this apparently flourishing economic activity (Figure $11 \& 12$ ). This drift can be directly co-related to the decrease in the growth and surviving ability status of the shrimps due to repetitive and un-scientific farming in the same pond over a long period. Moreover, as the income from shrimp farming mainly occurs from the export to developed countries, the uncertainty in the exchange value of Indian rupee against various foreign currencies also plays a big part in the entire shrimp-culture economy.

\section{Socio-economic features}

Shrimp farming is playing a great role on the socio-economic development of the coastal area. Families of farmers, daily labors, night guards, technicians, rickshaw pullers, ice, feed and medicine suppliers, lorry and pick-up van owners, drivers, helpers, even money investors are attached with this shrimp farming. There are every chances of effect on these families in profit or loss in this business, even life risks also. The decrease in traditional agriculture leads to a number of socioeconomic problems. The rich people are getting richer creates social dissymmetry. On the other hand, crop production is decreasing for soil salinity, so poor farmers are reluctant to cultivate the land. Due to social-insecurity land owners are forced to lease the land and farmers are losing jobs resulting in their increasing immigration from their own jobs to other places for other risky jobs. As this shrimp is mainly exported, shrimp deficit is going on in local market. Fresh water fish farming is neglected due to low profit and change in pond properties. Use of high antibiotic and unscientific management system causes all types of pollutions which create all types of disorders in ecosystem.

Following an attractive return and benefit from initial shrimp farming, mainly due to high export and higher foreign currency exchange rates, this lucrative business activity has grown exponentially after 2013 and 2017 and consequently, a large portion of agriculture land has been converted to shrimp farming area. As a result, more and more people are being attracted to this high risk economic activity. But the negative impacts have started to appear which may get worse in near future. There are high chances that the land may become almost barren in near future as a result of continuous shrimp farming in the same plots year after year. The highly risky shrimp culture and ancillary industries might not work in future. Without a guiding policy on the development of the shrimp sector, private businessmen are likely to move ahead in an unplanned or unscientific or unregulated method. The area might face problems from both ends - agricultural loss \& stoppage of shrimp farming.

\section{Discussion}

This study clearly shows that, the fertility of the surrounding agriculture soil of the shrimp farms is reducing due to salinity infiltration. Again, for unscientific shrimp farming techniques and repeated farming on the same ponds, the growth and surviving ability of the shrimps are decreasing. As a result yield of shrimps and income from this sector has been obviously falling down.

Local people have only realized the immediate high economic incentives of shrimp farming to that of traditional agriculture of paddy and hence shrimp farming has seen exponential growth. A blind profit driven advance in this field often ignored the required measures. The tanks owners are desperate for their personal benefit and uncared for public interest or the environment or scientific method adoption. On the other hand, the administration is so long indifferent and seems to have no awareness of the maladies. All the above mentioned studies indicate to the glowing problems and it seems that, the time has come when they should interfere in the problematic situation, the sooner the better.

There is an urgent need from the part of the government, to intervene and look after scientific method for site selection of shrimp farm, appropriate food and medicine for increasing production, and to take the proper steps for minimizing or stopping leakage of saline water from shrimp pond and to improve the inlet \& outlet water management system. Moreover, compulsorily permission from Government for farming with relevant record must be started and uncontrolled conversion of agricultural land to shrimp farm must be stopped immediately. Proper training for shrimp culture and testing of water and soil must be provided. Awareness about the adverse long term effect of unscientific brackish water shrimp farming among the general population of the affected area is also needed to highlight this dire problem. Improved marketing process and providing the required banking and insurance system for shrimp aquaculture will make this aquaculture more socio-economically viable.

\section{Conclusion}

We firmly believe that the brackish water vannamei shrimp farming in scientific way parallel with plan wise agriculture can contribute something worthy to the socio-economic sustainable development of Contai coastal area under Purba Medinipur district, West Bengal for proper revolution of BLUE (aquaculture) with GREEN (agriculture).

\section{Acknowledgement}

We highly acknowledge all the villagers (mainly the shrimp farmers of the ponds) of the study area for their help and support in data collection. We also like to thank the local administration for providing various necessary data. We are also thankful to Contai-I Bio-diversity Management Committee for their heartfelt cooperation. We also acknowledge the immense support provided by the members of the Coastal Ecology Research Laboratory, Egra SSB College, WB, India. We also thank Mr. Bibekananda Jana, IIT Khargpur and Mr. Debkumar Sahoo, IISER Kolkata for their helpful discussion during the preparation of this manuscript.

\section{References}

1. Ananda Raja R, Panigrahi A, Kumar S. Epidemiological Investigation of Brackish Water Culture Systems in West Bengal, India. J. Appl. Aquaculture 2012;24:49-59.

2. Yamaguchi T, Blumwald E. Developing salt-tolerant crop plants: challenges and opportunities. Trends Plant Sci. 2005;10:615-620.

3. Shahbaz M, Ashraf M. Improving salinity tolerance in cereals. Crit. Rev. Plant Sci 2013;32:237-249.

4. Raut S, Sarangi SK, Lama TD. Soil Salinity, Infiltration and Organic Matter Status under Different Landforms in Coastal West Bengal. J Indian Soc Coastal Agric Res 2019;37:86-91.

5. Cao C, Jiang S, Ying Z, Zhang F, Han X. Spatial variability of soil nutrients and microbiological properties after the establishment of leguminous shrub Caragana microphylla Lam. Plantation on sand dune in the Horqin sandy land of northeast China. Ecological Eng. 
2011;37:1467-1475.

6. Chen H, Yang C, Ren A, Guo K, Feng X, Li J et al. The Evapotranspiration of Tamarix and Its Response to Environmental Factors in Coastal Saline Land of China. Water. 2019;11:2273.

7. Yu C, Li Y, MoR, Deng W, Zhu Z, Liu D et al. Effects of long-term straw retention on soil microorganisms under a rice-wheat cropping system. Arch. Microbiol 2020;202:1915-1927.

8. Ikehashi H, Ponnamperuma FN. Varietal tolerance to rice for adverse soils. Soils and Rice. IRRI, Manila, Philippines. 1978, 801-822.

9. Hein L. Impact of shrimp farming on mangroves along east coast of India. Unasylva 2000;51:48-54.

10. Shanahan M, Thornton C, Trent S, Williams J. Risky Business: Vietnamese Shrimp Aquaculture Impacts and Investments. Environmental Justice Foundation, London 2003, 42.

11. Kumaran M, Anand PR, Kumar JA, Ravisankar T, Paul J, Vimala DD. Is Pacific white shrimp (Penaeus vannamei) farming in India is technically efficient?-A comprehensive study. Aquaculture 2017;468:262-270.

12. Kelleher G, Bleakley C, Wells S. A Global Representative System of Marine Protected Areas, Volume III, World Bank, Washington 1995, 147.

13. Spalding M, Blasco F, Field C. World Mangrove Atlas.The International Society for Mangrove Ecosystems, Okinawa, Japan 1997, 178.

14. ValielaI, Bowen JL, York JK. Mangrove Forests: One of the World's Threatened Major Tropical Environments: At least $35 \%$ of the area of mangrove forests has been lost in the past two decades, losses that exceed those for tropical rain forests and coral reefs, two other well-known threatened environments. Bio. Science 2001;51:807-815.

15. Lacerda LD, Conde JE, Kjerfve B, Alvarez-León R, Alarcón C, Polanía J. American Mangroves. In: de Lacerda L.D. (eds.) Mangrove Ecosystems. Environmental Science. Springer, Berlin, Heidelberg 2002.

16. Lal PN. Integrated and Adaptive Mangrove Management Framework-an Action Oriented Option for the New Millennium. In: de Lacerda L.D. (eds) Mangrove Ecosystems. Environmental Science. Springer, Berlin, Heidelberg 2002.

17. Dayaratne P. Review of the small pelagic fisheries of Sri Lanka, In Devaraj M., and Martosubroto P. (eds). Small pelagic resources and their fisheries in the Asia-Pacific region: proceedings of the APFIC Workshop 1997, 300336.

18. Ahmed N. Socio-economic aspects of freshwater prawn culture development in Bangladesh. PhD Thesis, Institute of Aquaculture, University of Stirling, Scotland, UK 2001.

19. Chen J, Mueller V. Coastal climate change, soil salinity and human migration in Bangladesh. Nature Clim. Change 2018;8:981-985.

20. Krishnani KK, Rajendran KV, Joseph KO, Gupta BP. Soil and water characteristics of shrimp ponds affected with viral disease. J Inland Fish. Soc. India 1999;29:2742.

21. District Census Handbook, Census of India, Series2011;20:XII B.

22. People's Biodiversity Register of Nayaput Gram Panchayet-Prepared by Contai-I Biodiversity
Management Committee, deposited at West Bengal Biodiversity Board, NBA, India 2015. 